\section{Bivalirudin Started during Emergency Transport for Primary PCI}

\author{
Philippe Gabriel Steg, M.D., Arnoud van 't Hof, M.D., Ph.D., Christian W. Hamm, M.D., \\ Peter Clemmensen, M.D., Ph.D., Frédéric Lapostolle, M.D., Ph.D., Pierre Coste, M.D., \\ Jurrien Ten Berg, M.D., Ph.D., Pierre Van Grunsven, M.D., Gerrit Jan Eggink, M.D., \\ Lutz Nibbe, M.D., Uwe Zeymer, M.D., Marco Campo dell' Orto, M.D., \\ Holger Nef, M.D., Jacob Steinmetz, M.D., Ph.D., Louis Soulat, M.D., Kurt Huber, M.D., \\ Efthymios N. Deliargyris, M.D., Debra Bernstein, Ph.D., Diana Schuette, Ph.D., \\ Jayne Prats, Ph.D., Tim Clayton, M.Sc., Stuart Pocock, Ph.D., Martial Hamon, M.D., \\ and Patrick Goldstein, M.D., for the EUROMAX Investigators*
}

\section{ABSTRACT}

\section{BACKGROUND}

Bivalirudin, as compared with heparin and glycoprotein IIb/IIIa inhibitors, has been shown to reduce rates of bleeding and death in patients undergoing primary percutaneous coronary intervention (PCI). Whether these benefits persist in contemporary practice characterized by prehospital initiation of treatment, optional use of glycoprotein IIb/IIIa inhibitors and novel ${\mathrm{P} 2 \mathrm{Y}_{12}}_{2}$ inhibitors, and radial-artery PCI access use is unknown.

\section{METHODS}

We randomly assigned 2218 patients with ST-segment elevation myocardial infarction (STEMI) who were being transported for primary PCI to receive either bivalirudin or unfractionated or low-molecular-weight heparin with optional glycoprotein IIb/IIIa inhibitors (control group). The primary outcome at 30 days was a composite of death or major bleeding not associated with coronary-artery bypass grafting (CABG), and the principal secondary outcome was a composite of death, reinfarction, or non-CABG major bleeding.

\section{RESULTS}

Bivalirudin, as compared with the control intervention, reduced the risk of the primary outcome (5.1\% vs. $8.5 \%$; relative risk, $0.60 ; 95 \%$ confidence interval [CI], 0.43 to $0.82 ; \mathrm{P}=0.001)$ and the principal secondary outcome ( $6.6 \%$ vs. $9.2 \%$; relative risk, $0.72 ; 95 \% \mathrm{CI}, 0.54$ to $0.96 ; \mathrm{P}=0.02$ ). Bivalirudin also reduced the risk of major bleeding ( $2.6 \%$ vs. $6.0 \%$; relative risk, 0.43 ; $95 \%$ CI, 0.28 to 0.66 ; $\mathrm{P}<0.001$ ). The risk of acute stent thrombosis was higher with bivalirudin $(1.1 \%$ vs. $0.2 \%$; relative risk, 6.11; $95 \%$ CI, 1.37 to $27.24 ; \mathrm{P}=0.007)$. There was no significant difference in rates of death $(2.9 \%$ vs. $3.1 \%)$ or reinfarction $(1.7 \%$ vs. $0.9 \%)$. Results were consistent across subgroups of patients.

\section{CONCLUSIONS}

Bivalirudin, started during transport for primary PCI, improved 30-day clinical outcomes with a reduction in major bleeding but with an increase in acute stent thrombosis. (Funded by the Medicines Company; EUROMAX ClinicalTrials.gov number, NCT01087723.)
The authors' affiliations are listed in the Appendix. Address reprint requests to Dr. Steg at Cardiologie, Département Hospitalo-Universitaire FIRE, Hôpital Bichat, Assistance Publique-Hôpitaux de Paris, 46 rue Henri Huchard, 75018 Paris, France, or at gabriel.steg@bch.aphp.fr.

\section{*A complete list of the European Ambu- lance Acute Coronary Syndrome Angi- ography (EUROMAX) investigators is provided in the Supplementary Appen- dix, available at NEJM.org.}

This article was published on October 30 2013, at NEJM.org.

N EnglJ Med 2013;369:2207-17. DOI: 10.1056/NEJMoal311096 Copyright (C) 2013 Massachusetts Medical Society. 
Ditas RIMARY PERCUTANEOUS CORONARY INtervention (PCI), which is the standard of care for the treatment of patients with STsegment elevation myocardial infarction (STEMI), ${ }^{1,2}$ requires adjunctive antithrombotic treatment with anticoagulants and antiplatelet agents. In the Harmonizing Outcomes with Revascularization and Stents in Acute Myocardial Infarction (HORIZONS-AMI) trial, ${ }^{3}$ bivalirudin (Angiomax, Angiox, the Medicines Company), as compared with unfractionated heparin and routine use of glycoprotein IIb/IIIa inhibitors, reduced rates of major bleeding and death at 30 days, with a survival benefit that extended to 3 years, ${ }^{4}$ albeit with an increased rate of acute stent thrombosis.

A number of changes have occurred in clinical practice since the HORIZONS-AMI trial was conducted: the use of radial-artery PCI access, which may reduce the risk of bleeding and vascular complications, ${ }^{5}$ has expanded; and the use of ticagrelor or prasugrel has been increasingly adopted. ${ }^{6,7}$ In parallel, the use of glycoprotein IIb/IIIa inhibitors has declined and is no longer routine. Anticoagulation is frequently started early, either because the patient presents at a hospital where PCI is not performed and thus requires transport to another hospital or - as is frequently the case in Europe - because treatment is started in the ambulance.

The European Ambulance Acute Coronary Syndrome Angiography (EUROMAX) trial, an international, randomized, open-label study, was designed to test whether bivalirudin, initiated during transport for primary PCI in patients with STEMI, was superior to heparins with optional use of glycoprotein IIb/IIIa inhibitors in contemporary practice, with frequent use of radial access and novel P2Y ${ }_{12}$ inhibitors. ${ }^{8}$

METHODS

\section{STUDY DESIGN}

The trial was designed by an academic executive committee (see the Supplementary Appendix, available with the full text of this article at NEJM .org) and the sponsor (the Medicines Company), with the latter collecting the data. An academic statistical group received data from the sponsor and provided data and analyses to the independent data and safety monitoring committee. At trial completion, data were analyzed by the sponsor and validated by an independent academic statistical group led by two of the authors that had the full data set.

The first author wrote the first draft of the manuscript, which was revised and approved by all coauthors, and provided for comment to the sponsor. Editorial support (limited to editing for style, referencing, and use of graphics) was provided by MedLink Healthcare Communications and was funded by the Medicines Company. The authors made the decision to submit the manuscript for publication; they accept full responsibility for the accuracy and completeness of the data and all analyses and for the fidelity of this report to the trial protocol, available at NEJM.org.

\section{STUDY PATIENTS}

The study enrolled men and nonpregnant women (18 years of age or older) presenting within 12 hours after the onset of symptoms with a presumed diagnosis of STEMI, with any of the following conditions: ST-segment elevation of at least $1 \mathrm{~mm}$ in two contiguous leads on electrocardiography, presumed new left bundle-branch block, or ST-segment depression of at least $1 \mathrm{~mm}$ in at least two leads in $V_{1}$ through $V_{3}$ with a positive terminal $\mathrm{T}$ wave. All patients had to be scheduled for angiography with the intention of performing primary PCI within 2 hours after the first medical contact. The main exclusion criteria were treatment with any injectable anticoagulant before randomization, oral anticoagulation, recent surgery, and a history of bleeding. A full set of inclusion and exclusion criteria is provided in the Supplementary Appendix.

Patients were identified, initial consent was obtained, randomization was performed, and study-drug administration was initiated in the ambulance or in a non-PCI hospital. Patients were transported urgently to the primary PCI hospital, where treatment was continued and outcomes data collected. All patients initially provided abridged written or oral informed consent in the ambulance or non-PCI hospital before study-drug administration. This consent was subsequently confirmed by a more formal final written informed consent. The study was approved by local ethics committees and health authorities. ${ }^{8}$

\section{STUDY TREATMENTS}

Patients who were assigned to the bivalirudin group received a bolus of $0.75 \mathrm{mg}$ per kilogram of body weight, followed by an infusion of 
$1.75 \mathrm{mg}$ per kilogram per hour. The protocol specified that the infusion should be continued for at least 4 hours after PCI. The protocol also specified that the dose during the post-PCI interval should be $0.25 \mathrm{mg}$ per kilogram per hour; however, continuation of the higher dose used during PCI was also permitted. Bailout use of a glycoprotein IIb/IIIa inhibitor was allowed in the event of giant thrombus or microvascular obstruction (no reflow).

Patients who were assigned to the heparin group (control group) received either unfractionated heparin (100 IU per kilogram without a glycoprotein IIb/IIIa inhibitor or 60 IU per kilogram with a glycoprotein IIb/IIIa inhibitor) or an intravenous bolus of enoxaparin $(0.5 \mathrm{mg}$ per kilogram). The use of glycoprotein IIb/IIIa inhibitors was left to physician preference and was categorized as either routine (started before PCI) or bailout. Any glycoprotein IIb/IIIa inhibitor could be used at the approved doses and regimens.

All patients received aspirin and an approved $\mathrm{P} \mathrm{Y}_{12}$ inhibitor as early as possible after the first medical contact. Decisions regarding access site, performance of thrombus aspiration, and stent type were left to physician preference.

\section{STUDY OUTCOMES}

The primary outcome was a composite of death from any cause or major bleeding not related to coronary-artery bypass grafting (CABG) at 30 days. The principal secondary 30-day outcome was a composite of death from any cause, reinfarction, or non-CABG major bleeding. Other secondary end points included major adverse cardiovascular events (death, reinfarction, ischemiadriven revascularization, or stroke), net adverse clinical events (composite of major adverse cardiovascular events and non-CABG major bleeding), each of the components of the primary and principal secondary outcomes, ischemia-driven revascularization, stent thrombosis (as defined by the Academic Research Consortium ${ }^{9}$ ), and a composite of reinfarction, ischemia-driven revascularization, or stent thrombosis.

The protocol definition of major bleeding was bleeding unrelated to CABG surgery that included intracranial, retroperitoneal, or intraocular bleeding; access-site hemorrhage requiring radiologic or surgical intervention; a reduction in the hemoglobin level of more than $4 \mathrm{~g}$ per deciliter $(2.5 \mathrm{mmol}$ per liter) without an overt source of bleeding; a reduction in the hemoglobin level of more than $3 \mathrm{~g}$ per deciliter $(1.8 \mathrm{mmol}$ per liter) with an overt source of bleeding; reintervention for bleeding; or use of any blood-product transfusion. Bleeding was also assessed according to Thrombolysis in Myocardial Infarction (TIMI) $^{10}$ and Global Utilization of Streptokinase and Tissue Plasminogen Activator for Occluded Coronary Arteries (GUSTO) ${ }^{11}$ criteria.

Table 1. Baseline Characteristics of the Intention-to-Treat Population.*

\begin{tabular}{|c|c|c|}
\hline Characteristic & $\begin{array}{l}\text { Bivalirudin } \\
(\mathrm{N}=1089)\end{array}$ & $\begin{array}{l}\text { Control } \\
(\mathrm{N}=1109)\end{array}$ \\
\hline \multicolumn{3}{|l|}{ Age } \\
\hline Median (IQR) - yr & $61(52-71)$ & $62(52-72)$ \\
\hline$>65 \mathrm{yr}-$ no. $(\%)$ & $394(36.2)$ & $434(39.1)$ \\
\hline Female sex — no. (\%) & $275(25.3)$ & $248(22.4)$ \\
\hline \multicolumn{3}{|l|}{ Cardiac-related history — no. (\%)† } \\
\hline Diabetes & $127(11.7)$ & $169(15.3)$ \\
\hline Hypertension & $459(42.2)$ & $504(45.5)$ \\
\hline Hyperlipidemia』 & $398(36.6)$ & $417(37.6)$ \\
\hline Current smoker & $453(41.6)$ & $472(42.6)$ \\
\hline Previous myocardial infarctiont & $80(7.4)$ & $113(10.2)$ \\
\hline $\begin{array}{l}\text { Previous percutaneous coronary } \\
\text { intervention }\end{array}$ & $97(8.9)$ & $108(9.7)$ \\
\hline Previous CABG & $18(1.7)$ & $29(2.6)$ \\
\hline Killip class II, III, or IV — no./total no. (\%) & $77 / 996(7.7)$ & $69 / 1000(6.9)$ \\
\hline Anemia - no./total no. (\%) & $129 / 987(13.1)$ & $148 / 989(15.0)$ \\
\hline \multicolumn{3}{|l|}{ Creatinine clearance - no./total no. (\%) } \\
\hline$\leq 60 \mathrm{ml} / \mathrm{min}$ & $147 / 1001(14.7)$ & $165 / 998(16.5)$ \\
\hline$>60 \mathrm{ml} / \mathrm{min}$ & $854 / 1001(85.3)$ & $833 / 998(83.5)$ \\
\hline \multicolumn{3}{|l|}{ Country - no. (\%) } \\
\hline France & $398(36.5)$ & $397(35.8)$ \\
\hline Netherlands & $377(34.6)$ & $391(35.3)$ \\
\hline Germany & $139(12.8)$ & $140(12.6)$ \\
\hline Denmark & $78(7.2)$ & $72(6.5)$ \\
\hline Other $\|$ & 97 (8.9) & $109(9.8)$ \\
\hline
\end{tabular}

* There were no significant between-group differences except in the two categories that are noted below. CABG denotes coronary-artery bypass grafting, and IQR interquartile range.

$\dagger$ Data on cardiac-related history were missing for one patient in each study group.

$\uparrow \mathrm{P}<0.05$ for the between-group comparison.

$\int$ Hyperlipidemia was defined as a diagnosis of hyperlipidemia or the use of lipid-lowering therapy.

9 Killip classes are as follows: class I, no clinical signs of heart failure; class II, rales or crackles in the lungs, a third heart sound, and an elevated jugular venous pressure; class III, frank acute pulmonary edema; and class IV, cardiogenic shock or hypotension and evidence of peripheral vasoconstriction. || Other countries include Austria, Czech Republic, Italy, Poland, and Slovenia. 


\begin{tabular}{|c|c|c|}
\hline Variable & Bivalirudin ( $\mathrm{N}=1089)$ & Control $(\mathrm{N}=1109)$ \\
\hline Randomized in ambulance - no. (\%) & $1030(94.6)$ & $1045(94.2)$ \\
\hline Randomized in non-PCl-capable hospital — no. (\%) & $59(5.4)$ & $64(5.8)$ \\
\hline Aspirin use - no. (\%) & $1088(100.0)$ & $1107(99.8)$ \\
\hline \multicolumn{3}{|l|}{$\mathrm{P} 2 \mathrm{Y}_{12}$ inhibitor loading dose - no./total no. (\%) } \\
\hline Any agent & $1048 / 1066(98.3)$ & $1058 / 1083(97.7)$ \\
\hline Clopidogrel & $524 / 1048(50.0)$ & $545 / 1058(51.5)$ \\
\hline Ticlopidine & 0 & $2 / 1058(0.2)$ \\
\hline Prasugrel & $323 / 1048(30.8)$ & $306 / 1058(28.9)$ \\
\hline Ticagrelor & $201 / 1048(19.2)$ & $205 / 1058(19.4)$ \\
\hline $\mathrm{P}^{2} \mathrm{Y}_{12}$ loading dose before angiography - no./total no. (\%) & $913 / 1011(90.3)$ & $923 / 1010(91.4)$ \\
\hline \multicolumn{3}{|l|}{$\mathrm{P} 2 \mathrm{Y}_{12}$ inhibitor maintenance dose - no./total no. (\%) } \\
\hline Any agent & $957 / 1065(89.9)$ & $969 / 1082(89.6)$ \\
\hline Clopidogrel & $377 / 957(39.4)$ & $407 / 969(42.0)$ \\
\hline Ticlopidine & $2 / 957(0.2)$ & $5 / 969(0.5)$ \\
\hline Prasugrel & $321 / 957(33.5)$ & $298 / 969(30.8)$ \\
\hline Ticagrelor & $257 / 957$ (26.9) & $259 / 969(26.7)$ \\
\hline \multicolumn{3}{|l|}{ Initial anticoagulation - no. (\%) } \\
\hline Bivalirudin & $1074(98.6)$ & $29(2.6)$ \\
\hline Unfractionated heparin & $24(2.2)$ & 997 (89.9) \\
\hline Enoxaparin & 0 & $94(8.5)$ \\
\hline $\begin{array}{l}\text { Median time from initiation of anticoagulation to angiography (IQR) } \\
\qquad-\mathrm{min}\end{array}$ & $50(37-67)$ & $50(37-65)$ \\
\hline \multicolumn{3}{|l|}{ Glycoprotein IIb/IIla inhibitor — no./total no. (\%)† } \\
\hline Any & $125 / 1088(11.5)$ & $766 / 1109(69.1)$ \\
\hline Routine use & $42 / 1088(3.9) \div$ & $649 / 1109(58.5)$ \\
\hline Bailout use $\mathbb{Z}$ & $83 / 1046(7.9)$ & $117 / 460(25.4)$ \\
\hline \multicolumn{3}{|l|}{ Arterial-access site - no./total no. (\%) } \\
\hline Femoral & $558 / 1069(52.2)$ & $582 / 1084(53.7)$ \\
\hline Radial & $510 / 1069(47.7)$ & $502 / 1084(46.3)$ \\
\hline Single-vessel disease — no./total no. (\%) & $591 / 1069(55.3)$ & $556 / 1083(51.3)$ \\
\hline Left-main-stem disease — no./total no. (\%) & $82 / 1069$ (7.7) & $86 / 1084(7.9)$ \\
\hline \multicolumn{3}{|l|}{ Infarct artery treated with primary $\mathrm{PCl}$ — no./total no. (\%) } \\
\hline Left main coronary artery & $6 / 943(0.6)$ & $13 / 946(1.4)$ \\
\hline Left anterior descending coronary artery & $425 / 943(45.1)$ & $423 / 946(44.7)$ \\
\hline Left circumflex coronary artery & $115 / 943(12.2)$ & $132 / 946(14.0)$ \\
\hline Right coronary artery & $417 / 943(44.2)$ & $412 / 946(43.6)$ \\
\hline Bypass grafting (venous or arterial) & $4 / 943(0.4)$ & $10 / 946(1.1)$ \\
\hline Balloon angioplasty only — no./total no. (\%) & $48 / 943(5.1)$ & $42 / 946(4.4)$ \\
\hline \multicolumn{3}{|l|}{ Implantation of stent — no./total no. (\%) } \\
\hline Any type & $868 / 943(92.0)$ & $865 / 946(91.4)$ \\
\hline Drug-eluting & $538 / 943(57.1)$ & $529 / 946(55.9)$ \\
\hline Thrombectomy — no./total no. (\%) & $304 / 943(32.2)$ & $298 / 946(31.5)$ \\
\hline
\end{tabular}




\begin{tabular}{|c|c|c|}
\hline Variable & Bivalirudin $(\mathrm{N}=1089)$ & Control $(\mathrm{N}=1109)$ \\
\hline \multicolumn{3}{|l|}{ TIMI flow — no./total no. (\%) } \\
\hline \multicolumn{3}{|l|}{ Before PCI } \\
\hline 0 to 1 & $593 / 931(63.7)$ & $563 / 932(60.4)$ \\
\hline 2 & $143 / 931(15.4)$ & $158 / 932(17.0)$ \\
\hline 3 & 195/931 (20.9) & $211 / 932(22.6)$ \\
\hline \multicolumn{3}{|l|}{ After $\mathrm{PCl}$} \\
\hline 0 or 1 & $18 / 930(1.9)$ & $16 / 932(1.7)$ \\
\hline 2 & $29 / 930(3.1)$ & $31 / 932(3.3)$ \\
\hline 3 & $883 / 930(94.9)$ & $885 / 932(95.0)$ \\
\hline CABG during hospitalization — no. (\%) & $21(1.9)$ & $29(2.6)$ \\
\hline \multicolumn{3}{|l|}{ Medications at discharge - no. (\%) } \\
\hline ACE inhibitor or ARB & 718 (65.9) & 709 (63.9) \\
\hline Aspirin & $1000(91.8)$ & $1012(91.3)$ \\
\hline Beta-blocker & $944(86.7)$ & $957(86.3)$ \\
\hline $\mathrm{P} \mathrm{Y}_{12}$ inhibitor & $938(86.1)$ & $941(84.9)$ \\
\hline Statin & 968 (88.9) & 997 (89.9) \\
\hline
\end{tabular}

* ACE denotes angiotensin-converting enzyme, ARB angiotensin-receptor blocker, $\mathrm{PCl}$ percutaneous coronary intervention, and TIMI Thrombolysis in Myocardial Infarction.

$\dagger \mathrm{P}<0.05$ for the between-group comparisons in this category.

$t$ The routine use of a glycoprotein IIb/IIla inhibitor in the bivalirudin group was a deviation from the protocol.

$\int$ Data are provided for patients who were eligible for bailout use of a glycoprotein IIb/IIla inhibitor (i.e., those who did not receive the drug routinely).

The primary study outcome was changed during the course of the trial. The original primary outcome measure was the composite of death from any cause, reinfarction, or non-CABG major bleeding, which became the principal secondary outcome after the change in the protocol. The change in the primary outcome was made in order to reduce the necessary sample size and occurred while the investigators were still unaware of study outcomes. Details of the circumstances surrounding the change in the primary outcome are provided in the Supplementary Appendix.

An independent clinical-events committee whose members were unaware of study-group assignments adjudicated deaths, bleeding episodes, reinfarction, ischemia-driven revascularization, stent thrombosis, and stroke. ${ }^{8}$ Detailed definitions of all study end points are provided in the Supplementary Appendix.

\section{STATISTICAL ANALYSIS}

We determined that a sample size of 2200 patients would provide a power of $80 \%$ for determining the primary outcome at a two-sided alpha level of 0.05 , assuming an event rate of $4.25 \%$ in the bivalirudin group and $7.0 \%$ in the control group. One planned interim analysis was performed by an independent statistician, after which the data and safety monitoring committee recommended that the trial continue as planned (see the Supplementary Appendix for details).

Analyses were performed in the intention-totreat population, which was defined as all patients who underwent randomization and provided written informed consent. We used the chi-square test to perform comparisons of event rates or Fisher's exact test in the case of sparse data. We used the log-rank test to compute the significance of time-to-event data. Continuous variables are reported as medians and interquartile ranges. Categorical variables are reported as frequencies and percentages. Analyses were performed with the use of SAS software, version 9.2.

\begin{tabular}{l}
\hline RESULTS \\
PATIENTS \\
A total of 2218 patients were enrolled in the trial \\
from 65 sites in nine European countries from \\
March 10, 2010, through June 20, 2013 (Fig. S1 in
\end{tabular}


the Supplementary Appendix). Of these patients, 1102 were randomly assigned to the bivalirudin group and 1116 to the control group with optional receipt of a glycoprotein IIb/IIIa inhibitor. Of the 2218 patients who provided initial abridged informed consent, 2198 provided formal written informed consent (1089 in the bivalirudin group and 1109 in the control group); these patients were included in the intention-totreat population. The baseline characteristics of patients were generally well matched between the two groups, although there were higher rates of diabetes and previous myocardial infarction in the control group (Table 1).

\section{TREATMENTS AND PROCEDURES}

Treatments and procedures are summarized in Table 2. The median time between study-drug initiation and coronary angiography was $50 \mathrm{~min}-$ utes. There was similar use of femoral arterial access and radial access. More than $90 \%$ of patients who underwent primary PCI received stents, with more than half receiving drug-eluting stents. Aspiration thrombectomy was performed in nearly one third of patients.

Most patients in the control group received unfractionated heparin (median dose, 61 IU per kilogram [interquartile range, 55 to 71]), with only a small proportion receiving enoxaparin (median dose, 50 IU per kilogram [interquartile range, 46 to 56]) (Table 2). Glycoprotein IIb/IIIa inhibitors were used in $11.5 \%$ of patients in the bivalirudin group and $69.1 \%$ in the control group. After PCI, 850 of 914 patients $(93.0 \%)$ in the bivalirudin group received a prolonged ( 2 hours or longer) infusion of bivalirudin, with 191 of 850 patients $(22.5 \%)$ receiving the PCI dose and 659 of 850 patients $(77.5 \%)$ receiving the reduced dose of $0.25 \mathrm{mg}$ per kilogram per hour. The median duration of bivalirudin infusion was 268 minutes (interquartile range, 250 to 292).

\section{OUTCOMES}

The main trial outcomes are summarized in Table 3 and shown in Figure 1, as well as in Figures S2, S3, and S4 in the Supplementary Appendix. The primary outcome occurred in $5.1 \%$ of the patients in the bivalirudin group and $8.5 \%$ in the control group with optional use of glycoprotein IIb/IIIa inhibitors (relative risk in the bivalirudin group, $0.60 ; 95 \%$ confidence interval [CI], 0.43 to $0.82 ; \mathrm{P}=0.001)$. The rate of occurrence of the principal secondary outcome was $6.6 \%$ in the bivalirudin group and $9.2 \%$ in the control group (relative risk, $0.72 ; 95 \% \mathrm{CI}, 0.54$ to $0.96 ; \mathrm{P}=0.02$ ).

There was no significant difference in rates of death, regardless of whether the cause was cardiac or noncardiac. There was a lower rate of non-CABG major bleeding in the bivalirudin group than in the control group $(2.6 \%$ vs. $6.0 \%$; relative risk, $0.43 ; 95 \% \mathrm{CI}, 0.28$ to $0.66 ; \mathrm{P}<0.001$ ), as well as lower rates of TIMI major or minor bleeding and any GUSTO bleeding (Table 3). Bivalirudin also reduced the rate of transfusion. Detailed information on individual types of bleeding events is provided in Table S1 in the Supplementary Appendix. There was no significant difference in rates of reinfarction, although the episodes were numerically more frequent in the bivalirudin group than in the control group.

Stent thrombosis was more frequent in the bivalirudin group than in the control group (1.6\% vs. $0.5 \%$; relative risk, 2.89 ; $95 \%$ CI, 1.14 to $7.29 ; \mathrm{P}=0.02)$; the difference was accounted for by stent thrombosis that occurred within 24 hours (Table 3), with no significant difference in rates of subacute stent thrombosis (occurring within 30 days). The median time to acute stent thrombosis in the bivalirudin group was 2.3 hours (interquartile range, 1.8 to 2.8). None of the acute stent thromboses were fatal. One death was attributed to subacute stent thrombosis in the control group. Of the patients who had stent thrombosis, $65.2 \%$ had reinfarction and $100 \%$ had ischemia-driven revascularization associated with the stent thrombosis.

\section{SENSITIVITY AND SUBGROUP ANALYSES}

Sensitivity analyses for the primary and principal secondary composite outcomes were performed in both the per-protocol population (all patients who underwent randomization, provided informed consent, received the randomized treatment, and underwent angiography) and the PCI population (all patients who underwent primary PCI) (Table S2 in the Supplementary Appendix). The results of these analyses were consistent with those in the intention-to-treat analysis.

An analysis of the effect of bivalirudin in 12 prespecified subgroups showed results that were consistent with those in the overall intention-totreat analysis with respect to the primary outcome (Fig. 2), principal secondary outcomes (Fig. S5 in the Supplementary Appendix), and non- 


\begin{tabular}{|c|c|c|c|c|}
\hline \multirow[t]{2}{*}{ Outcome } & $\begin{array}{l}\text { Bivalirudin } \\
(\mathrm{N}=1089)\end{array}$ & $\begin{array}{l}\text { Control } \\
(\mathrm{N}=1109)\end{array}$ & $\begin{array}{l}\text { Relative Risk } \\
\text { (95\% CI) }\end{array}$ & P Value \\
\hline & \multicolumn{2}{|c|}{ no. (\%) } & & \\
\hline Death or non-CABG major bleeding: primary outcome & $55(5.1)$ & $94(8.5)$ & $0.60(0.43-0.82)$ & 0.001 \\
\hline $\begin{array}{l}\text { Death, reinfarction, or non-CABG major bleeding: principal } \\
\text { secondary outcome }\end{array}$ & $72(6.6)$ & $102(9.2)$ & $0.72(0.54-0.96)$ & 0.02 \\
\hline Death & $32(2.9)$ & $34(3.1)$ & $0.96(0.60-1.54)$ & 0.86 \\
\hline Cardiac cause & $27(2.5)$ & $33(3.0)$ & $0.83(0.50-1.38)$ & 0.48 \\
\hline Noncardiac cause & $5(0.5)$ & $1(0.1)$ & $5.09(0.60-43.51)$ & 0.12 \\
\hline \multicolumn{5}{|l|}{ Non-CABG bleeding } \\
\hline Major & $28(2.6)$ & $67(6.0)$ & $0.43(0.28-0.66)$ & $<0.001$ \\
\hline Major or minor & $85(7.8)$ & $149(13.4)$ & $0.58(0.45-0.75)$ & $<0.001$ \\
\hline \multicolumn{5}{|l|}{ TIMI definition } \\
\hline Major & $14(1.3)$ & $23(2.1)$ & $0.62(0.32-1.20)$ & 0.15 \\
\hline Major or minor & $85(7.8)$ & $146(13.2)$ & $0.59(0.46-0.76)$ & $<0.001$ \\
\hline \multicolumn{5}{|l|}{ GUSTO definition } \\
\hline Any & $85(7.8)$ & $148(13.3)$ & $0.58(0.45-0.75)$ & $<0.001$ \\
\hline Severe or life-threatening & $6(0.6)$ & $10(0.9)$ & $0.61(0.22-1.68)$ & 0.33 \\
\hline Severe or life-threatening or moderate & $14(1.3)$ & $26(2.3)$ & $0.55(0.29-1.04)$ & 0.06 \\
\hline Blood transfusion & $23(2.1)$ & $43(3.9)$ & $0.54(0.33-0.90)$ & 0.02 \\
\hline \multicolumn{5}{|l|}{ Reinfarction } \\
\hline Any & $19(1.7)$ & $10(0.9)$ & $1.93(0.90-4.14)$ & 0.08 \\
\hline Q-wave & $3(0.3)$ & $2(0.2)$ & $1.53(0.26-9.12)$ & 0.68 \\
\hline Non-Q-wave & $16(1.5)$ & $8(0.7)$ & $2.04(0.88-4.74)$ & 0.09 \\
\hline \multicolumn{5}{|l|}{ Stent thrombosis $†$} \\
\hline Definite & $17(1.6)$ & $6(0.5)$ & $2.89(1.14-7.29)$ & 0.02 \\
\hline$\leq 24 \mathrm{hr}$ & $12(1.1)$ & $2(0.2)$ & $6.11(1.37-27.24)$ & 0.007 \\
\hline$>24 \mathrm{hr}$ to 30 days & $5(0.5)$ & $4(0.4)$ & $1.27(0.34-4.73)$ & 0.75 \\
\hline Probable & 0 & 0 & NA & NA \\
\hline $\begin{array}{c}\text { Major adverse cardiovascular events: death, reinfarction, ischemia- } \\
\text { driven revascularization, or stroke }\end{array}$ & $65(6.0)$ & $61(5.5)$ & $1.09(0.77-1.52)$ & 0.64 \\
\hline $\begin{array}{l}\text { Net adverse clinical events: death, reinfarction, ischemia-driven } \\
\text { revascularization, stroke, } t \text { or non-CABG major bleeding } \mathbb{}\end{array}$ & $85(7.8)$ & $118(10.6)$ & $0.73(0.56-0.96)$ & 0.02 \\
\hline Ischemia-driven revascularization & $24(2.2)$ & $17(1.5)$ & $1.44(0.78-2.66)$ & 0.25 \\
\hline Reinfarction, ischemia-driven revascularization, or stent thrombosis & $29(2.7)$ & $21(1.9)$ & $1.41(0.81-2.45)$ & 0.23 \\
\hline \multicolumn{5}{|l|}{ Stroke } \\
\hline Anyt: & $6(0.6)$ & $11(1.0)$ & $0.56(0.21-1.50)$ & 0.24 \\
\hline Ischemic & $6(0.6)$ & $9(0.8)$ & $0.68(0.24-1.90)$ & 0.46 \\
\hline Hemorrhagic & 0 & $2(0.2)$ & NA & 0.50 \\
\hline Acquired thrombocytopenia & $7(0.7)$ & $14(1.4)$ & $0.50(0.20-1.24)$ & 0.13 \\
\hline
\end{tabular}

* GUSTO denotes Global Utilization of Streptokinase and Tissue Plasminogen Activator for Occluded Coronary Arteries, and NA not applicable. $\dagger$ Stent thrombosis was defined according to the criteria of the Academic Research Consortium. ${ }^{9}$

$\uparrow$ Stroke includes ischemic and hemorrhagic events and those of unknown cause.

$\int$ Net adverse clinical events were a composite of major adverse cardiovascular events and non-CABG major bleeding.

I A total of 996 patients in the bivalirudin group and 999 patients in the control group were evaluated for acquired thrombocytopenia. 




B Principal Secondary Outcome

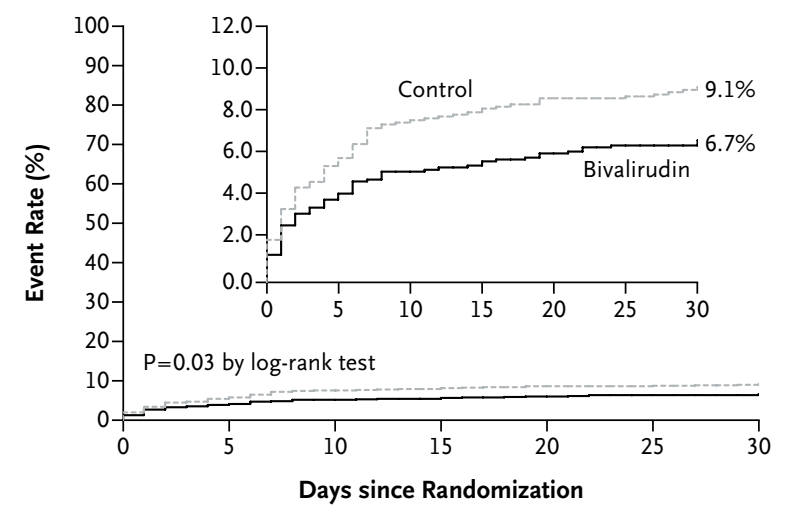

No. at Risk

Bivalirudin

Control

1109

1027

1020

$\begin{array}{rrrrr}1010 & 1005 & 990 & 971 & 779 \\ 996 & 990 & 975 & 949 & 760\end{array}$

Figure 1. Kaplan-Meier Curves of Study Outcomes.

Shown are the rates of events for the primary composite outcome (death or major bleeding not associated with coronary-artery bypass grafting [CABG])

(Panel A) and the principal secondary outcome (a composite of death, reinfarction, or non-CABG major bleeding) (Panel B) at 30 days. The inset graph shows a more detailed version of the overall graph.
CABG major bleeding (Fig. S6 in the Supplementary Appendix). In these analyses, there were no significant interactions with baseline or procedural variables, including the arterial-access site and type of $\mathrm{P}_{2} \mathrm{Y}_{12}$ inhibitor that was administered. The effect of bivalirudin on the primary outcome appeared to be consistent regardless of whether patients in the control group received routine glycoprotein IIb/IIIa inhibitors $(5.1 \%$ vs. 7.6\%; relative risk, 0.67 ; $95 \%$ CI, 0.46 to 0.97 ; $\mathrm{P}=0.03)$ or did not receive such therapy $(5.1 \%$ vs.
9.8\%; relative risk, $0.52 ; 95 \% \mathrm{CI}, 0.35$ to 0.75 ; $\mathrm{P}<0.001)$.

\section{DISCUSSION}

In our study, prehospital initiation of bivalirudin, as compared with heparin with optional use of glycoprotein IIb/IIIa inhibitors, reduced the primary composite outcome of death or major bleeding at 30 days in patients with STEMI who were being transported for primary PCI. The secondary composite outcome of death, reinfarction, and major bleeding at 30 days was also reduced with bivalirudin. These benefits, which were consistent across subgroups, stemmed from substantial reductions in major bleeding. However, the risk of acute stent thrombosis was higher in the bivalirudin group.

The HORIZONS-AMI trial showed that during primary PCI for STEMI, bivalirudin alone was superior to heparin plus a glycoprotein IIb/IIIa inhibitor, with a marked reduction in bleeding at 30 days. ${ }^{3}$ There was also a reduction in the rate of death from cardiac causes and any cause, which was sustained for up to 3 years. ${ }^{4,12}$ Given evolving changes in clinical practice, our study was designed to determine whether these benefits of bivalirudin would persist in the contemporary setting. Important changes in this regard include prehospital initiation of intravenous anticoagulation, ${ }^{13,14}$ increasing use of radial access for catheterization and PCI, ${ }^{5,15,16}$ reduced use of glycoprotein IIb/IIIa inhibitors during primary PCI, 1,2,17 and the advent of the novel $\mathrm{P}_{2} \mathrm{Y}_{12}$ inhibitors (ticagrelor and prasugrel ${ }^{6,7}$ ).

In our study, the initiation of bivalirudin in the prehospital setting achieved substantial reductions in bleeding, regardless of the choice for arterial access or $\mathrm{P}_{2} \mathrm{Y}_{12}$ inhibitor and even when the use of glycoprotein IIb/IIIa inhibitors was optional. However, at 30 days, we did not find the benefit of bivalirudin in reduced rates of death from cardiac and other causes that were seen in the HORIZONS-AMI trial. Data are currently being collected on 1-year mortality as a prespecified end point.

In the HORIZONS-AMI trial, there was an increased risk of acute stent thrombosis among patients receiving bivalirudin. The discontinuation of bivalirudin at the end of PCI and before the onset of the antiplatelet effect of oral $\mathrm{P} \mathrm{Y}_{12}$ inhibitors may have created a vulnerable window 




for stent thrombosis. In contrast, in the heparin group, acute stent thrombosis was either minimized or delayed by the prolonged infusion of glycoprotein IIb/IIIa inhibitors. ${ }^{18,19}$ In our study, there was also a higher risk of acute stent thrombosis in the bivalirudin group, which sug- gests that neither a prolonged, reduced-dose infusion of bivalirudin nor the use of the new oral $\mathrm{P} \mathrm{Y}_{12}$ inhibitors was sufficient to address this risk. Given the delayed onset of the antiplatelet effect of the oral $\mathrm{P}_{2} \mathrm{Y}_{12}$ inhibitors in patients with STEMI, ${ }^{20}$ avoiding the occurrence of stent 
thrombosis may require more potent and rapidly effective antithrombotic agents, such as intravenous antiplatelet drugs. ${ }^{21,22}$ Our study showed a nonsignificant increase in rates of reinfarction and ischemia-driven revascularization in the bivalirudin group, which appeared to be driven primarily by the increased rate of acute stent thrombosis. However, our study was not powered to examine these outcomes separately.

Some limitations of our study should be taken into consideration. The primary composite outcome was changed in order to reduce the sample size as a consequence of slow enrollment. An open-label design was implemented because of the logistic impracticality of a double-blind design in the context of emergency transport for primary PCI in a multinational trial. To minimize reporting bias that can be associated with an open-label design, events were adjudicated blindly by an independent clinical-events committee that used standardized end-point definitions. The trial was not powered to examine 30-day mortality and its cardiac and noncardiac subsets. Al- though the use of anticoagulation before catheterization was a notable feature of our study, the trial was neither designed nor intended to compare such use with use in the catheterization laboratory. Finally, although the trial allowed for the use of either unfractionated heparin or enoxaparin, too few patients received the latter (which is an accepted option in Europe ${ }^{1}$ ) to reliably test the consistency of the benefit among types of heparin.

In conclusion, in patients with STEMI who were being transported for primary PCI, bivalirudin, as compared with heparin with optional use of glycoprotein IIb/IIIa inhibitors, reduced 30-day rates of the primary and principal secondary outcomes, through a reduction in major bleeding, with higher rates of acute stent thrombosis.

Supported by the Medicines Company.

Disclosure forms provided by the authors are available with the full text of this article at NEJM.org.

We thank the investigators who are listed in the Supplementary Appendix; and Sophie Rushton-Smith, Ph.D., of MedLink Healthcare Communications, for editorial support.

The authors' affiliations are as follows: Université Paris-Diderot, Sorbonne Paris Cité, INSERM Unité-698, Département HospitaloUniversitaire Fibrosis Inflammation Remodeling, and Hôpital Bichat, Assistance Publique-Hôpitaux de Paris, Paris (P.G.S.), SAMU 93-Unité Fonctionnelle Recherche-Enseignement-Qualité, Université Paris 13, Sorbonne Paris Cité, Hôpital Avicenne (F.L.), Hôpital Cardiologique-Centre Hospitalier Universitaire Bordeaux, Université de Bordeaux, Pessac (P. Coste), Services d'Aide Médicale Urgente, Service Mobile d'Urgence et de Réanimation Urgences, Centre Hospitalier, Chateauroux (L.S.), Clinical Research Department, University of Caen, Caen (M.H.), and the Emergency Department and SAMU, Lille University Hospital, Lille (P.G.) - all in France; National Heart and Lung Institute, Imperial College, Institute of Cardiovascular Medicine and Science, Royal Brompton Hospital (P.G.S.), and London School of Hygiene and Tropical Medicine (T.C., S.P.) — all in London; Isala Klinieken, Department of Cardiology (A.H.), and Regionale Ambulancevoorziening IJsselvecht (G.J.E.), Zwolle, St. Antonius Hospital, Nieuwegein (J.T.B.), and RAV Gelderland Zuid, Nijmegen (P.V.G.) — all in the Netherlands; Kerckhoff Clinic and Thoraxcenter, Department of Cardiology, Bad Nauheim (C.W.H., M.C.O.), the Department of Nephrology and Medical Intensive Care, Charité, Campus Virchow-Klinikum, Universitätsmedizin Berlin, Berlin (L.N.), Klinikum Ludwigshafen, Ludwigshafen (U.Z.), and the University of Giessen, Medizinische Klinik I, Cardiology and Angiology, Giessen (H.N.) - all in Germany; Rigshospitalet, Department of Cardiology, Institute for Clinical Medicine, University of Copenhagen (P. Clemmensen), and the Department of Anesthesia (Head and Orthopedics Center) and Emergency Medical Service of the Capital Region, Capital Region Rigshospitalet, Copenhagen University Hospital (J.S.) — both in Copenhagen; 3rd Department of Medicine, Cardiology, Wilhelminenhospital, Vienna (K.H.); and the Medicines Company, Parsippany, NJ (E.N.D., D.B., D.S., J.P.).

REFERENCES

1. Steg PG, James SK, Atar D, et al). ESC guidelines for the management of acute myocardial infarction in patients presenting with ST-segment elevation. Eur Heart J 2012;33:2569-619.

2. O'Gara PT, Kushner FG, Ascheim DD, et al. 2013 ACCF/AHA guideline for the management of ST-elevation myocardial infarction: executive summary: a report of the American College of Cardiology Foundation/American Heart Association Task Force on Practice Guidelines. Circulation 2013;127:529-55.

3. Stone GW, Witzenbichler B, Guagliumi $\mathrm{G}$, et al. Bivalirudin during primary PCI in acute myocardial infarction. N Engl J Med 2008;358:2218-30.
4. Stone GW, Witzenbichler B, Guagliumi G, et al. Heparin plus a glycoprotein IIb/IIIa inhibitor versus bivalirudin monotherapy and paclitaxel-eluting stents versus bare-metal stents in acute myocardial infarction (HORIZONS-AMI): final 3-year results from a multicentre, randomised controlled trial. Lancet 2011;377:2193-204.

5. Mehta SR, Jolly SS, Cairns J, et al. Effects of radial versus femoral artery access in patients with acute coronary syndromes with or without ST-segment elevation. J Am Coll Cardiol 2012;60:2490-9.

6. Steg PG, James S, Harrington RA, et al. Ticagrelor versus clopidogrel in patients with ST-elevation acute coronary syndromes intended for reperfusion with primary percutaneous coronary intervention: a Platelet Inhibition and Patient Outcomes (PLATO) trial subgroup analysis. Circulation 2010;122:2131-41.

7. Montalescot G, Wiviott SD, Braunwald E, et al. Prasugrel compared with clopidogrel in patients undergoing percutaneous coronary intervention for ST-elevation myocardial infarction (TRITON-TIMI 38): double-blind, randomised controlled trial. Lancet 2009;373:723-31.

8. Steg PG, van 't Hof A, Clemmensen P, et al. Design and methods of EUROMAX: an international randomized open-label ambulance trial of bivalirudin versus standard-of-care anticoagulation in pa- 
tients with acute ST-segment elevation myocardial infarction transferred for primary percutaneous coronary intervention. Am Heart J 2013 October 16 (Epub ahead of print).

9. Cutlip DE, Windecker S, Mehran R, et al. Clinical end points in coronary stent trials: a case for standardized definitions. Circulation 2007;115:2344-51.

10. Rao AK, Pratt C, Berke A, et al Thrombolysis in Myocardial Infarction (TIMI) Trial - phase I: hemorrhagic manifestations and changes in plasma fibrinogen and the fibrinolytic system in patients treated with recombinant tissue plasminogen activator and streptokinase. J Am Coll Cardiol 1988;11:1-11.

11. The GUSTO Investigators. An international randomized trial comparing four thrombolytic strategies for acute myocardial infarction. N Engl J Med 1993;329: 673-82.

12. Mehran R, Lansky AJ, Witzenbichler $\mathrm{B}$, et al. Bivalirudin in patients undergoing primary angioplasty for acute myocardial infarction (HORIZONS-AMI): 1-year results of a randomised controlled trial. Lancet 2009;374:1149-59.

13. Sejersten M, Nielsen SL, Engstrom T, Jørgensen E, Clemmensen P. Feasibility and safety of prehospital administration of bivalirudin in patients with ST-eleva- tion myocardial infarction. Am J Cardiol 2009; 103:1635-40.

14. Hirschl MM, Mayr H, Erhart F, et al. Prehospital treatment of patients with acute myocardial infarction with bivalirudin. Am J Emerg Med 2012;30:12-7.

15. Steg PG, Huber K, Andreotti F, et al. Bleeding in acute coronary syndromes and percutaneous coronary interventions: position paper by the Working Group on Thrombosis of the European Society of Cardiology. Eur Heart J 2011;32:1854-64. 16. Hamon M, Pristipino C, Di Mario C, et al. Consensus document on the radial approach in percutaneous cardiovascular interventions: position paper by the European Association of Percutaneous Cardiovascular Interventions and Working Groups on Acute Cardiac Care and Thrombosis of the European Society of Cardiology. EuroIntervention 2013;8:124251.

17. Shahzad A, Cooper RM, Stables RH. Antithrombotic therapy in PCI: why not heparin? EuroIntervention 2013;9:423-6.

18. Parodi G, Valenti R, Bellandi B, et al. Comparison of prasugrel and ticagrelor loading doses in ST-segment elevation myocardial infarction patients: RAPID (Rapid Activity of Platelet Inhibitor Drugs) primary PCI study. J Am Coll Cardiol 2013;61:1601-6.
19. Dangas GD, Caixeta A, Mehran R, et al. Frequency and predictors of stent thrombosis after percutaneous coronary intervention in acute myocardial infarction. Circulation 2011;123:1745-56.

20. Alexopoulos D, Xanthopoulou I, Gkizas $\mathrm{V}$, et al. Randomized assessment of ticagrelor versus prasugrel antiplatelet effects in patients with ST-segment-elevation myocardial infarction. Circ Cardiovasc Interv 2012;5:797-804.

21. Valgimigli M, Tebaldi M, Campo G, et al. Prasugrel versus tirofiban bolus with or without short post-bolus infusion with or without concomitant prasugrel administration in patients with myocardial infarction undergoing coronary stenting: the FABOLUS PRO (Facilitation through Aggrastat By drOpping or shortening Infusion Line in patients with ST-segment elevation myocardial infarction compared to or on top of PRasugrel given at loading dOse) trial. JACC Cardiovasc Interv 2012; 5:268-77.

22. Steg PG, Bhatt DL, Hamm CW, et al. Effect of cangrelor on periprocedural outcomes in percutaneous coronary interventions: a pooled analysis of patient-level data. Lancet 2013 September 2 (Epub ahead of print).

Copyright (c) 2013 Massachusetts Medical Society.

SPECIALTIES AND TOPICS AT NEJM.ORG

Specialty pages at the Journal's website (NEJM.org) feature articles in cardiology, endocrinology, genetics, infectious disease, nephrology, pediatrics, and many other medical specialties. These pages, along with collections of articles on clinical and nonclinical topics, offer links to interactive and multimedia content and feature recently published articles as well as material from the NEJM archive (1812-1989). 